\title{
NEW METHODOLOGIES AND APPROACHES FOR MAPPING FORESTED KARST LANDSCAPES, VANCOUVER ISLAND, BRITISH COLUMBIA, CANADA
}

Tim Stokes

Professor-Vancouver Island University, 900 Fifth Street, Nanaimo, British Columbia, V9R 5S5, Canada, tim.stokes@viu.ca

\section{Paul Griffiths}

Consultant-Vancouver Island University, 544 Springbok Road, Campbell River, British Columbia, V9W 8A2, Canada, pgriff@shaw.ca

\section{Carol Ramsey}

Honorary Research Associate-Vancouver Island University, 900 Fifth Street, Nanaimo, British Columbia, V9R 5S5, Canada, clramsey@shaw.ca

\begin{abstract}
Mapping is an essential tool for land management and is typically used to assess the nature and characteristics of a land surface, along with its resource features and values. Mapping of karst landscapes is of particular importance for the temperate rainforests of Vancouver Island on the west coast of British Columbia (BC), where both forestry and natural resource development activities occur. A set of BC Government standards for mapping karst have been developed at varying scales (reconnaissance, planning-level and detailed), and incorporate procedures to assess the potential and vulnerability of karst, applying qualitative analysis of various surface and subsurface karst attributes. Previously, karst maps have been compiled by GIS mapping software and generated as static graphic images. However, it is now possible to make maps more accessible and interactive by uploading them as overlays within Google Earth (as KML files) or other imagery platforms. It is also possible for these maps to be taken into the field using tablets, phones, or iPads, thus allowing for on-site data collection and resource evaluation. A key focus of this research is the development of a 'Karst Map of Vancouver Island' that outlines the known extent of the karst and the likely contributing non-karst catchments. The mapping will also be used to identify regions of varying karst potential/vulnerability and notable karst areas/features. Trials have been completed to see how detailed imagery of karst features and areas collected by UAV technology can be used for karst evaluation. Karst areas have also been mapped using LiDAR, which has the potential for detecting surface karst features beneath the forested canopy and for assessing the overall sensitivity of forested karst areas.
\end{abstract}




\section{NCKRI SYMPOSIUM 5 14TH SINKHOLE CONFERENCE}

